\title{
Correction to: Planning for active management of future invasive pests affecting urban forests: the ecological and economic effects of varying Dutch elm disease management practices for street trees in Milwaukee, WI USA
}

\author{
Richard J. Hauer ${ }^{1} \cdot$ Ian S. Hanou ${ }^{2}$ - David Sivyer ${ }^{3}$ \\ Published online: 28 September 2020 \\ (C) Springer Science+Business Media, LLC, part of Springer Nature 2020
}

Correction to: Urban Ecosystems (2020) 23:1005-1022

https://doi.org/10.1007/s11252-020-00976-6

The published version of this article unfortunately contained missing information.

In Table 4, the column headings that explain the table data was not included in the published version.

The corrected Table 4 is presented in this erratum.

The online version of the original article can be found at https://doi.org/ 10.1007/s11252-020-00976-6

Richard J. Hauer

rhauer@uwsp.edu

1 Urban Forestry, University of Wisconsin - Stevens Point, 800

Reserve Street, Stevens Point, WI 54481, USA

2 PlanIt Geo, LLC, 7878 Wadsworth Boulevard, Suite 340,

Arvada, CO 80003, USA

3 City of Milwaukee, Department of Public Works Operations

Division, 841 N. Broadway Rm. 620, Milwaukee, WI 53202, USA 
Table 4 American elm (Ulmus americana L.) street tree population and ecosystem benefits (units, millions) over time and resulting elm population projected by Dutch elm disease (Ophiostoma novi-ulmi) sanitation management alternative. (all \$ in USD 2014 base year)

\begin{tabular}{|c|c|c|c|c|c|c|c|c|c|c|c|}
\hline $\begin{array}{l}\text { Management } \\
\text { Alternative }\end{array}$ & Year & $\begin{array}{l}\text { Elm } \\
\text { population } \\
(\#)\end{array}$ & $\begin{array}{l}\text { Stormwater } \\
\text { (L) }\end{array}$ & $\begin{array}{l}\text { Stormwater } \\
\text { value }(\$)\end{array}$ & $\begin{array}{l}\text { Structural } \\
\text { value }(\$)\end{array}$ & $\begin{array}{l}\text { Air pollution } \\
\text { removal } \\
\text { (metric tons) }\end{array}$ & $\begin{array}{l}\text { Carbon } \\
\text { storage } \\
(\$)\end{array}$ & $\begin{array}{l}\text { Carbon } \\
\text { storage } \\
\text { (metric } \\
\text { tons) }\end{array}$ & $\begin{array}{l}\text { Carbon } \\
\text { sequestration } \\
\text { (metric tons) }\end{array}$ & $\begin{array}{l}\text { Energy } \\
\text { savings } \\
(\$)\end{array}$ & $\begin{array}{l}\text { Total } \\
\text { Eco } \\
\text { value } \\
(\$)\end{array}$ \\
\hline \multirow[t]{7}{*}{ Actual } & 1956 & 106,732 & 78.47 & 0.18 & 117.62 & 1.27 & 2.30 & 36.43 & 0.16 & 0.16 & 1.61 \\
\hline & 1963 & 102,355 & 101.36 & 0.24 & 160.80 & 1.64 & 3.44 & 54.47 & 0.18 & 1.05 & 2.93 \\
\hline & 1969 & 50,634 & 64.26 & 0.15 & 102.69 & 1.05 & 2.34 & 36.96 & 0.11 & 0.49 & 1.69 \\
\hline & 1979 & 9181 & 14.14 & 0.03 & 27.03 & 0.23 & 0.67 & 10.62 & 0.02 & 0.08 & 0.34 \\
\hline & 1986 & 4994 & 8.75 & 0.02 & 18.45 & 0.13 & 0.48 & 7.60 & 0.02 & 0.04 & 0.19 \\
\hline & 2008 & 1683 & 5.09 & 0.01 & 11.11 & 0.08 & 0.33 & 5.17 & 0.009 & 0.04 & 0.13 \\
\hline & 2013 & 1268 & 4.26 & 0.01 & 9.17 & 0.07 & 0.28 & 4.46 & 0.008 & 0.03 & 0.10 \\
\hline \multirow[t]{7}{*}{ No Control } & 1956 & 106,738 & 78.47 & 0.18 & 117.63 & 1.27 & 2.30 & 36.43 & 0.16 & 0.16 & 1.61 \\
\hline & 1963 & 83,623 & 82.66 & 0.19 & 131.37 & 1.34 & 2.81 & 44.50 & 0.14 & 0.86 & 2.39 \\
\hline & 1969 & 26,311 & 33.44 & 0.08 & 53.36 & 0.55 & 1.21 & 19.21 & 0.05 & 0.25 & 0.88 \\
\hline & 1979 & 3240 & 5.09 & 0.01 & 9.54 & 0.08 & 0.24 & 3.75 & 0.01 & 0.03 & 0.12 \\
\hline & 1986 & 748 & 1.42 & 0.003 & 2.76 & 0.02 & 0.07 & 1.14 & 0.002 & 0.01 & 0.03 \\
\hline & 2008 & 7 & $<0.000$ & $<0.000$ & 0.05 & $<0.000$ & 0.001 & 0.023 & $<0.000$ & $<0.000$ & 0.001 \\
\hline & 2013 & 3 & $<0.000$ & $<0.000$ & 0.02 & $<0.000$ & 0.001 & 0.009 & $<0.000$ & $<0.000$ & $<0.000$ \\
\hline \multirow[t]{7}{*}{ Fair } & 1956 & 106,738 & 78.47 & 0.18 & 117.63 & 1.27 & 2.30 & 36.43 & 0.16 & 0.16 & 1.61 \\
\hline & 1963 & 95,400 & 94.33 & 0.22 & 149.87 & 1.53 & 3.21 & 50.77 & 0.16 & 0.98 & 2.73 \\
\hline & 1969 & 67,875 & 86.10 & 0.20 & 137.65 & 1.41 & 3.13 & 49.55 & 0.14 & 0.65 & 2.27 \\
\hline & 1979 & 36,952 & 57.23 & 0.13 & 108.79 & 0.91 & 2.70 & 42.74 & 0.10 & 0.32 & 1.36 \\
\hline & 1986 & 24,142 & 41.89 & 0.10 & 89.18 & 0.64 & 2.32 & 36.72 & 0.08 & 0.19 & 0.93 \\
\hline & 2008 & 6335 & 19.22 & 0.05 & 41.80 & 0.30 & 1.23 & 19.47 & 0.032 & 0.14 & 0.48 \\
\hline & 2013 & 4674 & 15.86 & 0.04 & 33.78 & 0.25 & 1.04 & 16.44 & 0.029 & 0.10 & 0.38 \\
\hline \multirow[t]{7}{*}{ Good } & 1956 & 106,738 & 78.47 & 0.18 & 117.63 & 1.27 & 2.30 & 36.43 & 0.16 & 0.16 & 1.61 \\
\hline & 1963 & 96,822 & 95.68 & 0.23 & 152.11 & 1.55 & 3.26 & 51.53 & 0.17 & 0.99 & 2.77 \\
\hline & 1969 & 75,172 & 95.45 & 0.22 & 152.45 & 1.56 & 3.47 & 54.88 & 0.16 & 0.72 & 2.51 \\
\hline & 1979 & 47,935 & 74.21 & 0.17 & 141.12 & 1.18 & 3.50 & 55.44 & 0.13 & 0.41 & 1.77 \\
\hline & 1986 & 34,983 & 60.89 & 0.14 & 129.23 & 0.93 & 3.36 & 53.21 & 0.11 & 0.27 & 1.35 \\
\hline & 2008 & 13,000 & 39.65 & 0.09 & 85.79 & 0.61 & 2.53 & 39.96 & 0.066 & 0.28 & 0.99 \\
\hline & 2013 & 10,381 & 35.08 & 0.08 & 75.02 & 0.55 & 2.31 & 36.50 & 0.064 & 0.22 & 0.85 \\
\hline \multirow[t]{7}{*}{ Best } & 1956 & 106,738 & 78.47 & 0.18 & 117.63 & 1.27 & 2.30 & 36.43 & 0.16 & 0.16 & 1.61 \\
\hline & 1963 & 99,222 & 98.29 & 0.23 & 155.88 & 1.59 & 3.34 & 52.81 & 0.17 & 1.02 & 2.84 \\
\hline & 1969 & 88,852 & 112.73 & 0.27 & 180.19 & 1.85 & 4.10 & 64.86 & 0.18 & 0.85 & 2.97 \\
\hline & 1979 & 73,344 & 113.55 & 0.27 & 215.92 & 1.81 & 5.36 & 84.82 & 0.20 & 0.63 & 2.71 \\
\hline & 1986 & 64,128 & 111.53 & 0.26 & 236.89 & 1.71 & 6.16 & 97.54 & 0.20 & 0.50 & 2.47 \\
\hline & 2008 & 42,050 & 127.99 & 0.30 & 277.49 & 1.99 & 8.17 & 129.27 & 0.21 & 0.91 & 3.19 \\
\hline & 2013 & 38,204 & 78.47 & 0.30 & 276.10 & 2.01 & 8.49 & 134.34 & 0.24 & 0.81 & 3.12 \\
\hline
\end{tabular}

